\title{
Comparative Study of Haemodynamic Status and Arrhythmia between Combined Epidural with General Anaesthesia and General Anaesthesia alone in Off-pump Coronary Artery Bypass (OPCAB) Surgery
}

RK KUNDU ${ }^{\mathrm{a}}, \mathrm{AK}_{\mathrm{BEG}}^{\mathrm{b}}$, S HOSSAIN ${ }^{\mathrm{c}}$, N HAQUE ${ }^{\mathrm{d}}, \mathrm{MAHAFUDDOZA}^{\mathrm{e}}$, AYFE CHOWDHURY ${ }^{\mathrm{f}}$

\begin{abstract}
Summary:
Objectives: To find out if combined general anaesthesia (GA) with high thoracic epidural anaesthesia (HTEA) was better in controlling haemodynamic condition and reducing incidences of arrhythmia during induction of $G A$ and during positioning and handling of the heart itself by the surgeons. Materials and Method: Forty (40) patients of 40-65 yrs age were randomly selected and divided in two groups (group $A, n=20$ : combined HTEA and $G A-$ study group, group $B, n=20: G A$ alone- control group). Group A received HTEA introduced through an indwelling epidural catheter at C7-T1 or T1-T2 interspace. Lignocaine (1\%) $5 \mathrm{ml}$ and Bupivacain (0.25\%) $5 \mathrm{ml}$ with Fentanyl $10 \mathrm{mg}$ was given through the catheter as bolus followed by Bupivacain (0.25\%) $5 \mathrm{ml}$ with Fentanyl $10 \mathrm{mg}$ was given at 2 hours interval. General anaesthesia was induced and maintained in a standardized manner for all patients of both the groups.
\end{abstract}

\section{Introduction:}

High thoracic epidural anaesthesia (HTEA) is an important tool in off-pump coronary artery bypass (OPCAB) surgery in general. HTEA yielding cardiac sympathectomy resulting in vasodilatation of coronary and internal thoracic artery and bradycardia without haemodynamic compromise ${ }^{1,2}$. Thoracic epidural anaesthesia may also help decrease the incidence of supraventricular and ventricular

a. Dr. Ranadhir Kumar Kundu, Registrar, Square Hospital, b. Dr. Abdul Khaleque Beg, Professor. c. Dr. Shahadat Hossain, Junior Consultant. d. Dr. Naimul Haque, Professor. e. Dr. Mahafuddoza, Assistant Professor. f. Prof. Abu Yusuf Fazle Elahi Chowdhury, Professor and Head. Department of Anaesthesiology, National Institute of Cardiovascular Diseases (NICVD), Dhaka.

Address of Correspondence: Dr. Ranadhir Kumar Kundu, MD, Associate Consultant, Department of Anaesthesiology, SQUARE Hospital, 18/F West Panthapath, Dhaka-1205. E-mailranadhirk@gmail.com
The parameters monitored were Heart Rate (HR), Arterial Blood Pressure (ABP), and Electrocardiogram (ECG arrhythmia and ST changes), Oxygen saturation (SPO2) and Central Venous Pressure (CVP) during the procedure Results: Induction of GA was smoother and with fewer blood pressure peaks in all patients of group A. They demonstrated a stable haemodynamic status throughout operation in general and during positioning of the heart and bypass grafting in particular. Incidences and severity of cardiac arrhythmias were also less during these periods. Conclusion: Combined HTEA-GA technique for $O P C A B$ procedure is safe and affords to achieve stable haemodynamic status during induction of GA. It also allows reducing incidence of arrhythmias during cardiac position and grafting. Regarding the above qualities, group $A$ appeared superior to group $B$.

(J Bangladesh Coll Phys Surg 2008; 26: 116-120)

arrhythmia undergoing cardiothoracic surgery ${ }^{6}$. It also attenuates the stress response, a favorable oxygen supply/ demand ratio for the myocardium, balancing the procoagulant activity after off-pump surgery and effective control of pain ${ }^{1-5}$. The goal of this study was to determine the better effectiveness of HTEA with general anaesthesia (GA) for OPCAB surgery regarding haemodynamic status and incidence and severity of arrhythmia.

Materials and Methods:

Between July, 2006 to March, 2007 forty patients were randomly selected in both sexes with the age of 40-65 years, physical status ASA(American Society of Anesthesiologist)- II and III and NYHA(New York Heart Association)- II and III, ejection fraction (EF) $\geq 40 \%$ and patient willing to participate in the study. Prior approval of institutional ethics committee was taken for the study. The patients having left main disease, any contraindication to neuroaxial block or 
catheter placement, hypersensitivity to any drugs used in the study and taking antiplatelet and anticoagulant drugs within 3-5 days before operation were excluded. Informed written consent was taken from all patients. Forty patients were grouped in two (each were 20), group A -combined epidural with GA (study group) and group B- only GA (control group). Patients were premedicated with tab. Diazepam-10 $\mathrm{mg}$. at night before operation.

Patient was placed in a lateral position and an $18 \mathrm{G}$ flexible tip catheter was inserted through a Tuohy needle at the $\mathrm{C}_{7}-\mathrm{T}_{1}$ or $\mathrm{T}_{1}-\mathrm{T}_{2}$ interspaces by using the median approach and the loss of resistance or hanging drop technique. The catheter was directed cephalad and advanced 3-4 cm. into the epidural space. The initial bolus dose of Lignocain 1\% $5 \mathrm{ml}$, Bupivacain $0.25 \% 5 \mathrm{ml}$. with Fentanyl 10 $\mathrm{gm}$. was administered. Top up dose of Bupivacain 0.25\% $5 \mathrm{ml}$. and Fentanyl $10 \mu \mathrm{gm}$ was given at 2 hours interval. GA was induced with Midazolam $0.2 \mathrm{mg} / \mathrm{kg}$, Morphine 0.3 $\mathrm{mg} / \mathrm{kg}$ and Pancuronium bromide $0.15 \mathrm{mg} / \mathrm{kg}$ body weight and maintained with $\mathrm{O}_{2} 3 \mathrm{~L} / \mathrm{min}, \mathrm{N}_{2} \mathrm{O} 3 \mathrm{~L} / \mathrm{min}$ with halothane $0.2 \%$ and one third of induction dose of Midazolam, Morphine and Pancuronium bromide $\mathrm{I} / \mathrm{V}$ at one hour interval. The same drugs and same doses were given for GA in both groups. The parameters including heart rate (HR), arterial blood pressure $(\mathrm{ABP})$, oxygen saturation $(\mathrm{SpO} 2)$, central venous pressure (CVP) and electro cardiogram (ECG) changes were noted before and at induction and postinduction at $10 \mathrm{~min}$. interval.

All statistical analysis was carried out using SPSS software. All results were expressed as mean $\pm \mathrm{SD}$ or in frequency as applicable. The results were compiled and analyzed using student's't'test and chi squared test as appropriate. Results were considered significant if $\mathrm{p}<0.05$.

\section{Results:}

Patients' characteristics were presented in Table-I. Two groups were fairly matched and there was no significant difference $(\mathrm{p}>0.05)$ between the groups regarding age, sex, height, weight, ASA and NYHA physical status.
Base line clinical data (Table-II) measured before induction showed no significant difference $(\mathrm{p}>0.05)$ between groups.

Per-operative haemodynamic parameters regarding HR, ABP, SpO2, CVP and ECG revealed that there were significant difference $(p<0.01)$ between groups (Table- III).

Regarding the incidence of arrhythmias presented in Table- IV and Table-V. During induction and maintenance of anaesthesia premature ventricular contraction (PVC) developed in two (10\%) patients in group A and ventricular fibrillation (VF) and PVC developed in four $(20 \%)$ and six $(30 \%)$ patients respectively in group B. But during handling the heart by surgeon (Table- V) VF and PVC developed in two $(10 \%)$ patients in group $\mathrm{A}$ and in group $\mathrm{B}, \mathrm{VF}$ developed in six $(30 \%)$ patients, VT (ventricular tachycardia) in two (10\%), PVC in eight (40\%) and atrial fibrillation (AF) in two (10\%) patients.

More inotropic and antiarrhythmic drugs were required in group B than group A during surgery (Table-VI).

\section{Table-I}

\begin{tabular}{lccc}
\multicolumn{4}{c}{ Demography } \\
Variable & Group A (n=20) & Group B (n=20) & p \\
\hline Age (yr) & $52.30 \pm 5.35$ & $50.00 \pm 5.00$ & NS \\
Sex = M (n) & $18(90 \%)$ & $16(80 \%)$ & NS \\
F (n) & $2(10 \%)$ & $4(20 \%)$ & \\
Weight (kg) & $65.90 \pm 8.56$ & $62.40 \pm 10.869$ & NS \\
Height (cm) & $161.70 \pm 6.73$ & $160.0 \pm 7.35$ & NS \\
ASA- II (n) & $10(50 \%)$ & $12(60 \%)$ & NS \\
III (n) & $10(50 \%)$ & $8(40 \%)$ & \\
NYHA- II (n) & $12(60 \%)$ & $10(50 \%)$ & NS \\
III (n) & $8(40 \%)$ & $10(50 \%)$ & \\
\hline
\end{tabular}

Values are expressed as mean \pm SD or number (n). Results of age, weight, height analyzed were done by student's ' $t$ ' test but for sex, ASA (American society of anesthesiologist) and NYHA (New York heart association) by chi-square test. Values are expressed as significant if $\mathrm{p}<0.05$. NS $=$ non significant 
Table - II

\begin{tabular}{lccc}
\multicolumn{4}{c}{ Preoperative clinical data } \\
Variable & Group A $(\mathrm{n}=20)$ & Group B $(\mathrm{n}=20)$ & $\mathrm{p}$ \\
\hline HR (bpm) & $72.3 \pm 7.44$ & $75.6 \pm 13.56$ & $\mathrm{NS}$ \\
ABP (mmHg) & $\mathrm{S}=138.6 \pm 19.21$ & $\mathrm{~S}=149.1 \pm 38.66$ & $\mathrm{NS}$ \\
& $\mathrm{D}=75.6 \pm 8.73$ & $\mathrm{D}=82.05 \pm 16.38$ & \\
& $\mathrm{M}=95.8 \pm 9.85$ & $\mathrm{M}=102.6 \pm 22.40$ & \\
SpO2 (\%) & $99.6 \pm 0.52$ & $99.4 \pm 0.52$ & $\mathrm{NS}$ \\
$\begin{array}{l}\text { ECG -Sinus } \\
\text { Rhythm (n) }\end{array}$ & $18(90 \%)$ & $16(80 \%)$ & \\
$\begin{array}{l}\text { ST }- \text { Segment } \\
\text { change (n) }\end{array}$ & $\downarrow 8(40 \%)$ & $\downarrow 12(60 \%)$ & \\
EF (\%) & $\uparrow 4(20 \%)$ & $\uparrow 4(20 \%)$ & \\
\hline
\end{tabular}

Values are expressed as mean $\pm \mathrm{SD}$ or number (n). Results were analyzed by student's 't' test \& Values are expressed as significant if $\mathrm{p}<0.05$. NS $=$ non significant. $\downarrow=$ depression. $\uparrow=$ elevation.

\section{Table - III}

\begin{tabular}{lccc}
\multicolumn{4}{c}{ Haemodynamic parameters } \\
Variable & Group A $(\mathrm{n}=20)$ & Group B $(\mathrm{n}=20)$ & $\mathrm{p}$ \\
\hline HR (bpm) & $76.35 \pm 9.58$ & $89.83 \pm 10.90$ & $\mathrm{~S}$ \\
ABP $(\mathrm{mmHg})$ & $\mathrm{S}=112.75 \pm 14.43$ & $\mathrm{~S}=123.49 \pm 21.59$ & $\mathrm{~S}$ \\
& $\mathrm{D}=66.14 \pm 10.90$ & $\mathrm{D}=73.37 \pm 11.54$ & \\
& $\mathrm{M}=82.59 \pm 10.79$ & $\mathrm{M}=90.13 \pm 12.10$ & \\
SpO2 (\%) & $99.58 \pm 0.59$ & $99.06 \pm 0.83$ & $\mathrm{~S}$ \\
ECG -Sinus & $18(90 \%)$ & $10(50 \%)$ & \\
Rhythm (n) & & & \\
ST - Segment & $\downarrow \quad 4(20 \%)$ & $\downarrow 10(50 \%)$ & \\
change (n) & $\uparrow 2(10 \%)$ & $\uparrow 8(40 \%)$ & \\
CVP(cmH2O) & $8.64 \pm 1.14$ & $9.07 \pm 1.22$ & $\mathrm{~S}$ \\
\hline
\end{tabular}

Values are expressed as mean $\pm \mathrm{SD}$ or number (n). Analysis were done by student's ' $t$ ' test. Values are expressed as significant if $\mathrm{p}<0.05 . \mathrm{S}=$ significant. $\downarrow$ $=$ depression. $\uparrow=$ elevation

\section{Table-IV}

Arrhythmia during induction \& maintenance

\begin{tabular}{lcc} 
Variable & Group A (n=20) & Group B $(\mathrm{n}=20)$ \\
VF (n) & $0(0 \%)$ & $4(20 \%)$ \\
PVC (n) & $2(10 \%)$ & $6(30 \%)$ \\
\hline
\end{tabular}

$\mathrm{VF}=$ Ventricular fibrillation, $\mathrm{PVC}=$ Premature ventricular contraction

$\mathrm{n}=$ number of patient
Table-V

Arrhythmia during cardiac handling

\begin{tabular}{lcc} 
Variable & Group A $(\mathrm{n}=20)$ & Group B $(\mathrm{n}=20)$ \\
\hline VF $(\mathrm{n})$ & $2(10 \%)$ & $6(30 \%)$ \\
VT (n) & $0(0 \%)$ & $2(10 \%)$ \\
PVC (n) & $2(10 \%)$ & $8(40 \%)$ \\
AF (n) & $0(0 \%)$ & $2(10 \%)$
\end{tabular}

$\mathrm{VF}=$ Ventricular fibrillation, $\mathrm{VT}=$ Ventricular tachycardia, $\mathrm{PVC}=$ Premature ventricular contraction, $\mathrm{AF}=$ Atrial fibrillation $\mathrm{n}=$ number of patient

\section{Table-VI}

\begin{tabular}{lcc}
\multicolumn{3}{c}{ Requirement of cardiac drugs } \\
Variable & Group A (n=20) & Group B (n=20) \\
\hline Dopamine (n) & $4(20 \%)$ & $16(80 \%)$ \\
Dobutamine (n) & $4(20 \%)$ & $16(80 \%)$ \\
Adrenaline (n) & $0(0 \%)$ & $4(20 \%)$ \\
Esmolol (n) & $0(0 \%)$ & $4(20 \%)$ \\
Lignocaine (n) & $0(0 \%)$ & $12(60 \%)$ \\
MgSO4 (n) & $0(0 \%)$ & $2(10 \%)$ \\
\hline $\mathrm{n}=$ number of patient & &
\end{tabular}

\section{Discussion:}

General anesthesia (GA) is the most commonly used anesthetic technique and considered the "gold standard" for coronary artery bypass grafting (CABG) performed either on-pump or off-pump. Within the last few years, however, high thoracic epidural anaesthesia (HTEA) as an adjunct to GA has become more prevalent ${ }^{(7)}$ and has been shown to be potentially beneficial in patients with coronary artery disease. Potential advantages of HTEA include stressresponse attenuation, intense perioperative analgesia, cardiac sympatholysis, and thus improved vascular graft blood flow and reduced heart rate, arrhythmia and a reduced risk of myocardial ischemia perioperatively $(8,9,10,15)$. In addition to these intraoperative advantages, postoperative pain management facilitated by continuous epidural application of analgesia improved significantly, postoperative pulmonary and gastrointestinal function with concomitant decreases in morbidity and mortality $(11,16,17)$ were shown to be achievable with 
HTEA. But with only HTEA technique, one must consider the stress associated with consciousness during cardiac surgery. It is difficult, if not impossible, to recommend that a patient remain conscious during any type of cardiac surgical procedure. At the 2002 autumn meeting of the Association of Cardiac Anaesthesiologists (a group limited to 50 of the most senior cardiac anaesthesiologists in the United States), not a single member advocated the use of a pure regional anaesthetic technique for any type of cardiac surgery. (18) Furthermore, because revascularization of the circumflex artery requires the Trendelenburg position that may result in significant haemodynamic compromise. In addition, because the anaesthetic level does not extend to the lower limbs, HTEA alone is limited to complete arterial revascularization. The use of HTEA as a supplement to general anaesthesia and controlled ventilation may provide both intraoperative and postoperative benefits. General anaesthesia has been used for decades in cardiac anaesthesia and represents a well-known and established standard anaesthetic technique for both on-and off-pump surgery. But only with GA technique, patients may become haemodynamically unstable with increased incidence of arrhythmias, prolonged postoperative artificial ventilation with pulmonary complication, long time ICU stay and increased cost. So GA was induced in association with HTEA because of having following advantages with GA - easy overall patient management, effective haemodynamic manipulation, maintenance of blood gas and acid base status, overcome psychological stress and effective in uncooperative and nonconsenting patients with short term ventilation and early discharge from ICU. Left main disease was excluded in the study because separate protocol for anaesthetic management is used. Low cost and easily available drugs were used in the study. HTEA in conjunction with GA appeared to be more effective in maintaining adequate haemodynamic parameters (e.g. heart rate, blood pressure, oxygen saturation and central venous pressure $(\mathrm{p}<0.01))$ and preventing precipitation of ischemic changes (ST-segment) and arrhythmias when compared to the control group (only GA group). Blockade of cardiac accelerator fibers may be responsible for the decreased prevalence of supraventricular tachycardias and other types of cardiac dysrrhythmias observed in patients managed with combined HTEA and GA technique. In the present study it was also revealed that number of patients developed ventricular and supraventricular arrhythmias and requirement of antiarrhythmic drugs were less in group A (study group) than group B. A recent meta-analysis calculated the risk for epidural haematoma formation in cardiac surgical patients with a $95 \%$ confidence to be 1 of 1,500 to 150,000 for epidural anaesthetics, ${ }^{(12)}$ compared with an incidence of 1: 143,000 in the overall population receiving epidural anaesthesia for noncardiac surgery. (13) Estimating the "true" risk is difficult and remains theoretical because of the extreme rarity of reported adverse events associated with the use of epidural catheter. The risk calculated by Renck, (14) 1 in 143,000 , may be too low in CABG patients, even with moderate heparinization using $150 \mathrm{IU} / \mathrm{kg}$ as in the patients in this study. Nevertheless, cardiac anaesthesia "lost its innocence" when Rosen and colleagues ${ }^{(14)}$ recently reported on the first case of an epidural haematoma on postoperative day 2 after aortic valve surgery.

\section{Conclusion:}

It can be concluded that for off-pump CABG, combined general and high thoracic epidural anaesthesia may be the most comprehensive anaesthetic technique. It maintains more haemodynamic stability and incidence of arrhythmias are fewer during positioning and handling of heart by surgeon. The inotropic and antiarrhythmic drug requirements are also less. Thus the application of regional techniques high thoracic epidural anaesthesia (HTEA) as supplement to general anaesthesia (GA) may be considered therapeutic as well as facilitative than only GA technique for offpump coronary artery bypass grafting (CABG).

\section{References:}

1. Meissner A, Rolf N, Van Aken N. Thoracic epidural anesthesia and the patient with heart disease; benefits, risks and controversies. Anesth Analg 1997; 85: 517-28.

2. Riedel BJ, Wright IG, Epidural anesthesia in coronary artery bypass grafting surgery.Curr Opin Cardiol 1997; 12: 515-21.

3. Ganapathy S, Murkin JM, Dobkowski W, Boyd D. Stress and inflammatory response after beating heart surgery 
versus conventional bypass surgery; the role of thoracic epidural anesthesia. Heart Surg Forum 2001; 4: 323-7.

4. Loick HM, Schmidt C, Van Aken H, et al. High thoracic epidural anesthesia, but not clonidine, attenuates the perioperative stress response via sympatholysis and reduces the release of troponin $\mathrm{T}$ in patients undergoing coronary artery bypass grafting. Anesth Analg 1999; 88: 701-9.

5. Mariani MA, Gu YJ, Boonstra PW, Grandjean JG, van Oeveren W, Ebels T. Procoagulant activity after off-pump coronary operation: is the current anticoagulation adequate? Ann Thorac Surg 1999; 67: 1370-5.

6. Mark A, Chaney, MD.Thoracic epidural anesthesia and perioperative arrhythmia. SCA Newsletter- October 2001

7. S. Goldstein, D. Dean and S.J. Kim et al., A survey of spinal and epidural techniques in adult cardiac surgery, J Cardiothorac Vasc Anesth 15 (2001), pp. 158-168.

8. Fawcett WJ, Edwards RE, Quinn AC, MacDonald IA, Hall GM. Thoracic epidural analgesia started after cardiopulmonary bypass. Adrenergic, cardiovascular and respiratory sequelae. Anaesthesia. 1997; 52: 914-6.

9. N. B. Scott, D.J.Turfrey and D.A. Ray et al., A prospective randomized study of the potential benefits of thoracic epidural anaesthesia in patients undergoing coronary artery bypass grafting, Anesth Analg 93 (2001), pp. 528-535.

10. Fillinger MP, Yeager MP, Dodds TM, Fillinger MF, Whalen PK, Glass DD. Epidural anesthesia and analgrsia: effects on recovery from cardiac surgery. J Cardiothorac Vasc Anesth. 2002; 16: 15-20
11. Vanek T, Straka Z, Brucek P, Widimsky P. Thoracic epidural anaesthesia for off-pump coronary artery bypass without intubation. Eur J Cardiothorac Surg. 2001; 20: 858-60.

12. Ho AM, Chung DC, Joynt GM. Neuaxial blockade and hematoma in cardiac surgery: estimating the risk of a rare adverse event that has not (yet) occurred. Chest. 2000; 117: 551-5.

13. H. Renck. Neurological complications of central nerve blocks. Acta Anaesthesiol Scand 39 (1995), pp. 859-868.

14. D. A. Rosen, D.W. Hawkinberry II and K. R. Rosen et al., An epidural haematoma in an adolescent patient after cardiac surgery, Anesth Analg 98 (2004), pp. 966-969.

15. K. Kirno, P. Friberg and A. Grzegorczyk et al., Thoracic epidural anesthesia during coronary artery bypass surgery. Effects on cardiac sympathetic activity, myocardial blood flow and metabolism, and central haemodynamics. Anesth Analg 79 (1994), pp. 1075.

16. R. Stenseth, L. Bjella and E.M.Berg et al. Effect of thoracic epidural analgesia on pulmonary function after coronary artery bypass surgery. Eur J Cardiothorac Surg 10 (1996), pp. 859-865.

17. A. Tenling, P. O. Joachimsson and H. Tyden et al., Thoracic epidural anaesthesia, as an adjunct to general anaesthesia for cardiac surgery. Effects on ventilation-perfusion relationships, J Cardiothorac Vasc Anesth 13 (1999), pp. 258-264.

18. C. M. Mangano, Risky business, J Thorac Cardiovasc Surg 125 (2003), pp. 1204-1207. 